\title{
An Analysis of Rural-Urban Differences in Average Family Income: An Application of the Oaxaca and Cotton-Neumark Decomposition Techniques
}

\section{Bradley T. Ewing and William Levernier*}

\begin{abstract}
Using multivariate regression analysis, this study examines the effect that demographic, educational, economic, and geographic characteristics have on average family income in rural and urban counties in the United States. The results indicate that while the above-mentioned characteristics generally affect average family income in both rural and urban counties, the effect of many characteristics is substantially different in rural counties than in urban counties. Using the Oaxaca and Cotton-Neumark decomposition techniques, we find that only about half the income difference between rural and urban counties is explained by differences in their characteristics, however.
\end{abstract}

\section{INTRODUCTION}

While there are arguably many different ways to measure the economic well-being of a region's residents, one possible measure is the average family income of the region under consideration. Economic development policies often focus on inducing economic growth or on attracting manufacturing facilities to a region to increase the average income of the region's inhabitants. In order to be able to ascertain whether or not such policies are effective, they must be designed such that they have measurable outcomes. The outcomes of the policies can then be compared to the established goals, and the extent of goal achievement can then be determined.

To implement policies that will effectively increase average family income in a region, policy makers must understand the relationship between a region's characteristics and its average family income. To what extent, for example, is a region's income affected by its economic growth? Or, to what extent is its income affected by the educational attainment of its inhabitants? Once these relationships are understood, policy makers can focus their efforts on changing those characteristics that most strongly influence a region's average family income. One thing that policy makers must be aware of, however, is that these relationships may differ between different types of regions. Specifically, the relationships may differ between rural and urban regions.

To further analyze these issues, the purpose of this study is twofold. First, it is to investigate the underlying determinants of average family income in rural

\footnotetext{
*Department of Economics, Texas Tech University, Lubbock, TX; and Department of Finance and Economics, Georgia Southern University, Statesboro, GA. An earlier version of this paper was presented at the 38th Annual Meeting of the Southern Regional Science Association, held in Richmond, Virginia. The authors would like to thank session participants, Bruce Weber, and three anonymous referees for helpful suggestions. Their suggestions made this a substantially better paper. All errors remain the responsibility of the authors.
} 
and urban counties in the United States. Particular attention is paid to how the structure of income determination in rural counties in the United States differs from that of urban counties. From a policy perspective, if the average family income in rural counties responds to a particular policy action differently than in urban counties, then policy makers responsible for rural areas may need to employ different policies than policy makers responsible for urban areas. On the other hand, if no major differences exist, then the same policies can be employed in urban areas as in rural areas.

The second purpose is based on the fact that rural counties have historically experienced lower average income than urban counties. Specifically, the second purpose is to determine the extent to which differences in the characteristics between rural and urban counties explain the rural-urban income difference. A contribution of this study is the application of the Oaxaca and Cotton-Neumark decomposition techniques to the analysis of rural-urban income differences. Both techniques decompose the rural-urban income differential into a portion that is caused by differences in the characteristics of rural and urban regions and a portion that cannot be explained by such differences. While the Oaxaca and CottonNeumark decompositions have often been used to examine the income (or earnings) differences between different groups of people, to the best of our knowledge the techniques have not previously been used to examine the income differential between different types of regions.

The decompositions in this study have potentially important policy implications. If the results indicate that most of the rural-urban income difference is caused by a rural-urban difference in the characteristics of counties, then policies that make rural counties similar to urban counties will cause a convergence of income between rural and urban counties. On the other hand, if the decompositions indicate that much of the rural-urban income difference cannot be attributed to a rural-urban difference in the characteristics of counties, then policies to make the characteristics of rural counties similar to those of urban counties will not cause a convergence of income between rural and urban counties.

\section{PAST FINDINGS}

The standard human capital theory of wage determination asserts that certain worker characteristics, such as educational attainment and job training, should affect a worker's earnings (Becker 1975). Schultz (1960) and Mincer (1962) contend that families and individuals make human capital investment decisions analogous to firm investment decisions in order to increase their productive capacity and earnings. Loewenstein and Spletzer (1999) find that the wages of workers increase with both the amount of general training and employer-specific training that they receive. A natural extension of this discussion is to think of income differences between rural and urban areas as partially arising from differences in human capital endowments between rural and urban residents. 
Additionally, Mincer and Polachek (1974) recognized that differences in the earnings of individuals arise from such factors as differences in gender and race. It should not be surprising, therefore, to find that income differences between rural and urban regions may be partially explained by differences in the gender and racial composition of the residents of rural and urban areas. On a related note, in a study of metropolitan area labor markets during the 1980s, Bound and Holzer (2000) find that the effect of demand shifts on falling relative wages in declining metropolitan areas was greatest among less-educated workers, less-experienced workers, and blacks.

A substantial literature on poverty, a topic closely related to income, has documented the characteristics of persons who experience the highest rates of poverty. Poverty rates are higher for members of racial minority groups than for whites (Danziger 1988; Sawhill 1988; Schiller 1998). Geographically, poverty rates are typically higher for people residing in rural areas than for people residing in metropolitan areas (U.S. Census Bureau 1998). In terms of individual attributes, poverty rates are lower for educated persons than for those with a lower level of education, and are lower for those who work than for those who are unemployed (Schiller 1998).

Many researchers have examined topics related to regional differences in earnings. Bellante and Kogut (1996) found that the ratio of black to white male earnings is lower in the South than in other parts of the United States. Gaynor and Durden (1997) examined earnings in the South and Southwest and found a geographic difference in the "cost of being female." Likewise, Carlstrom and Rollow (1998) examined black-white earning differences between the South and nonSouth and found a regional difference in the "cost of being black." Further, they found that there is a regional difference in the contribution of particular factors to the black-white income difference.

Several other studies have also examined regional differences in earnings. Simon (1993) examined state income levels by comparing natives' and immigrants' earnings. His findings suggest that the persistence of state income differentials can be partially explained by differences in the quality of schooling. Based on his findings, it is likely that income differences between rural and urban areas also may result if there are educational differences between rural and urban areas. Renkow (1996) contends that returns to schooling are lower in rural areas than in urban areas, and that rural earnings respond more to local labor market conditions than do urban earnings.

Differences in unemployment rates by state or region have been examined by a number of researchers (Bell 1981; Brechling 1967; Byers 1990, 1991; Chapman 1991; Gordon 1985; Hotchkiss 1991; Hyclak and Lynch 1980; Tiller and Bednarzik 1983). In many cases, differences in the behavior of regional unemployment rates are found both interregionally and in terms of their linkages to the national unemployment rate. These studies document the existence of differential employment 
patterns among regions and underscore the importance of controlling for regional economic characteristics when conducting income studies.

In a related study, Negrey, Zickel, and Fenn (1998) examined the effects of industrial restructuring (i.e., employment shifts by industry) on men's and women's personal income during the 1969-1989 period in 140 U.S. metropolitan areas. In their study, they analyzed shifts in employment in manufacturing, FIRE, wholesale and retail trade, and services, and found that the income loss of men was offset by the income gain of women. Overall, their study suggests that one important determinant of regional household income is employment shifts across industries.

While many aspects of regional and rural-urban income differences have been examined in the literature, prior studies have not decomposed the difference using the Oaxaca and Cotton-Neumark decomposition techniques. The use of these techniques in a rural-urban framework allows one to determine how much of the rural-urban income difference can be explained by differences between the characteristics of rural and urban areas. This study proceeds by describing the econometric methodology in Section 3, the data and results in Section 4, and then offers some concluding remarks and policy implications in Section 5.

\section{A MODEL OF COUNTY-LEVEL AVERAGE FAMILY INCOME AND THE OAXACA AND COTTON-NEUMARK DECOMPOSITIONS}

The geographic unit of observation used in this study is rural and urban counties in the 48 contiguous states. Average family income (AFI) in a county is estimated in general form as

$$
\mathrm{AFI}=\mathrm{f}(\text { Demog, HumCap, Econ, Geog) , }
$$

where AFI is the county's average family income, ${ }^{1}$ Demog is a vector of demographic characteristics of the county's population, HumCap is a vector of human capital characteristics of the county's population, Econ is a vector of economic characteristics of the county, and Geog is a vector of geographic characteristics of the county. The variables that are included in each of the vectors, along with their definition, are listed in Table 1.

The above equation is estimated by ordinary least squares, with the covariance matrix corrected for heteroscedasticity (Greene 1997), ${ }^{2}$ as

$$
\mathrm{AFI}=\alpha+\beta_{1} \text { Demog }+\beta_{2} \text { HumCap }+\beta_{3} \text { Econ }+\beta_{4} \text { Geog }+\varepsilon,
$$

\footnotetext{
${ }^{1}$ In the regression analysis, nominal AFI for each county is used as the dependent variable. Some of the difference in AFI that exists between counties may occur because of cost-of-living differences. Since a county-level cost-of-living variable is not available for all U.S. counties, it was not possible to include a cost-of-living variable as an explanatory variable. In interpreting the regression results, then, one should be aware that some of the zural-urban income difference that is found in this study could actually be caused by a cost-of-living difference. ${ }^{2}$ The correction yields a consistent estimator of the covariance matrix. The procedure does not change the value of the individual coefficients, relative to their value in an uncorrected OLS model, but does cause changes in the standard errors of the coefficients. Thus, some coefficients that are statistically significant in the uncorrected OLS model may not be statistically significant in the covariance corrected model (Greene 1995).
} 
where $\beta_{1}, \beta_{2}, \beta_{3}$, and $\beta_{4}$ are vectors of coefficients associated with Demog, HumCap, Econ, and Geog, respectively, and $\varepsilon$ is the error term.

\section{TABLE 1}

Definitions of Variables in OLS Regressions

\begin{tabular}{|c|c|}
\hline Variable & Definition \\
\hline \multicolumn{2}{|l|}{ Dependent Variable } \\
\hline Average Family Income & The average family income in the county in 1989 , in dollars. \\
\hline \multicolumn{2}{|l|}{ Demographic Variables } \\
\hline$\% 65$ and Older & $\begin{array}{l}\text { The percent of the county population in } 1990 \text { that is } 65 \text { years old or } \\
\text { older. }\end{array}$ \\
\hline$\%$ Black & The percent of the county population in 1990 that is black. \\
\hline$\%$ Other Minority & $\begin{array}{l}\text { The percent of the county population in } 1990 \text { that is a nonblack } \\
\text { minority. }\end{array}$ \\
\hline$\%$ Female Headed & $\begin{array}{l}\text { The percent of families in the county in } 1990 \text { that are headed by a } \\
\text { female, with no husband present. }\end{array}$ \\
\hline \multicolumn{2}{|l|}{ Human Capital Variables } \\
\hline$\%$ High School & $\begin{array}{l}\text { The percent of the } 25 \text {-year-old and older population in the county in } \\
1990 \text { that graduated from high school, but not from college. }\end{array}$ \\
\hline$\%$ College & $\begin{array}{l}\text { The percent of the } 25 \text {-year-old and older population in the county in } \\
1990 \text { that graduated from college. }\end{array}$ \\
\hline \multicolumn{2}{|l|}{ Economic Variables } \\
\hline Male LFPR & The male labor force participation rate in the county in 1990. \\
\hline Female LFPR & The female labor force participation rate in the county in 1990. \\
\hline Employment Growth & The rate of employment growth in the county from 1980 to 1990 . \\
\hline Restructuring & $\begin{array}{l}\text { Allen and Freeman's (1995) index of structural change from } 1980 \text { to } \\
1990 \text { in the county. }\end{array}$ \\
\hline$\%$ Goods Producing & $\begin{array}{l}\text { The percent of the } 1990 \text { labor force in the county that is employed in } \\
\text { mining, construction, or manufacturing. }\end{array}$ \\
\hline$\%$ State Union & $\begin{array}{l}\text { The percent of the labor force in the state that belongs to a labor } \\
\text { union }\end{array}$ \\
\hline \multicolumn{2}{|l|}{ Geographic Variables } \\
\hline West & $\begin{array}{l}\text { A dummy variable that takes a value of } 1 \text { if the county is in the West } \\
\text { Census region, } 0 \text { otherwise. }\end{array}$ \\
\hline Midwest & $\begin{array}{l}\text { A dummy variable that takes a value of } 1 \text { if the county is in the } \\
\text { Miwest Census region, } 0 \text { otherwise. }\end{array}$ \\
\hline Northeast & $\begin{array}{l}\text { A dummy variable that takes a value of } 1 \text { if the county is in the } \\
\text { Northeast Census region, } 0 \text { otherwise. }\end{array}$ \\
\hline
\end{tabular}

Sources: Hirsch and McPherson (1993) for \% State Union; U.S. Census Bureau (1990) for all other variables.

Each county included in the study is classified as either rural or urban, and separate regressions are run on each. In making this "either/or" classification for a particular county, though, there is necessarily some degree of subjectivity involved. While the population of a particular county may completely reside in either rural areas or urban areas, in many counties some of the population resides in rural areas and some of the population resides in urban areas. Thus, many counties in the United States have a mix of rural and urban areas. Rather than only including those counties that are completely urban or completely rural in this study, more inclusive definitions of "rural" and "urban" are utilized. A county is classified as "rural" if it is not in a metropolitan statistical area (MSA) and at least 80 percent of its population resides in a rural area. A county is classified as 
"urban" if at least 80 percent of its population resides in an urban area (the county need not be located in an MSA). Using this definition, a sample of 1,264 counties and independent cities, of which 331 are urban and 933 are rural, ${ }^{3}$ is obtained.

The AFI is substantially lower in a typical rural county than in a typical urban county. It is likely that part of this difference can be attributed to differences in characteristics between rural and urban counties. The typical urban county, for example, may have a better-educated labor force, a higher rate of employment growth, and a higher labor force participation rate than a typical rural county. If there are rural-urban differences in the characteristics that affect AFI in a county, one would expect that there would be a corresponding rural-urban income difference.

This study decomposes the rural-urban income difference using a technique that was first introduced by Oaxaca (1973) to determine the proportion of the income difference between males and females that can be attributed to gender discrimination. The basic premise of the Oaxaca technique is that the difference in income between individuals belonging to different groups (e.g., male versus female, black versus white) that cannot be attributed to differences in their characteristics (e.g., educational attainment, work experience, industry of occupation, etc.) is due to discrimination. Cotton (1988) and Neumark (1988) made extensions to the technique, but still allowed a researcher to measure that part of the income difference that can be attributed to differences in characteristics between the groups and that part that cannot. In a recent study that used the techniques, Gaynor and Durden (1997) determined the extent of racial and gender discrimination on earning differences between various groups of workers in the southwestern United States. Along the same lines, Carlstrom and Rollow (1998) determined the extent of the difference between workers' earnings in the South and non-South, and compared the effect of racial discrimination on workers' earnings between the two regions.

The Oaxaca and Cotton-Neumark decomposition techniques are normally applied to different groups of individuals to measure the extent to which racial or gender discrimination affects workers' earnings. In this paper, the techniques are extended to decompose the difference in AFI between rural and urban counties into an explained portion (i.e., that part of the rural-urban income difference that is accounted for by rural-urban differences in a variety of county characteristics) and an unexplained portion. In the conventional application, where the difference in the earnings between different groups of workers is decomposed, the unexplained portion is interpreted as discrimination. While the unexplained portion in the rural-urban approach is not discrimination in the conventional sense, it can be interpreted as a measure of a residual disadvantage that rural counties experience relative to urban counties. The unexplained portion is the income deficit that rural

${ }^{3}$ The regional breakdown of the 933 rural counties is as follows: 418 counties are in the South Census region, 119 counties are in the West Census region, 360 counties are in the Midwest Census region, and 36 counties are in the Northeast Census region. The regional breakdown of the 331 urban counties is as follows: 153 counties are in the South Census region, 63 counties are in the West Census region, 68 counties are in the Midwest Census region, and 47 counties are in the Northeast Census region. 
counties would experience even if rural and urban counties had the same average characteristics. The unexplained portion then gives rural policy makers an indication of how much of the rural income deficit would remain if they implemented policies that made the demographic, human capital, and economic characteristics of rural counties equal to those of urban counties.

Utilizing the Oaxaca model to explain rural-urban income differences, the difference in the mean AFI between urban counties and rural counties is estimated as

$$
Y_{U}-Y_{R}=\sum B_{U}\left(X_{U}-X_{R}\right)+\sum X_{R}\left(B_{U}-B_{R}\right) \text {. }
$$

Utilizing the Cotton-Neumark extension of the Oaxaca model ${ }^{4}$ to explain rural-urban income differences, the difference in the mean AFI between urban counties and rural counties is estimated as,

$$
Y_{U}-Y_{R}=\sum B^{*}\left(X_{U}-X_{R}\right)+\sum X_{U}\left(B_{U}-B^{*}\right)+\sum X_{R}\left(B^{*}-B_{R}\right)
$$

$Y_{U}$ and $Y_{R}$ are the mean AFI in urban and rural counties, respectively; $X_{U}$ and $X_{R}$ are the mean value for characteristic $X$ in urban and rural counties, respectively; $B_{U}$ and $B_{R}$ are the value of the coefficients from the regressions (Equation 2) for the urban and rural counties, respectively; and $B^{*}$ is the weighted average of the coefficients from the regressions for the 933 rural counties and the 331 urban counties.

The Cotton-Neumark technique decomposes the AFI difference between rural and urban counties into three terms. The first term on the right-hand side of the equal sign in Equation 4 represents that part of the total difference that can be attributed to differences in average characteristics between a typical urban county and a typical rural county. It measures the difference that would exist if the urban and rural counties both had the same set of coefficients in the regression model, but each had their existing set of average characteristics. The last two terms on the right-hand side of the equal sign collectively measure the amount of the rural income deficit that is not caused by differences in the average characteristics between urban and rural counties.

Before we proceed, it should be noted that the results obtained from the decomposition techniques can be sensitive to the choice of explanatory variables in the model. Specifically, if relevant variables are omitted from the regressions on which the decompositions are based, then the results of the decompositions will be affected. In particular, if relevant variables are omitted from the regressions so that the explanatory power of the regressions is reduced, the unexplained portion in the decompositions will tend to be larger.

\footnotetext{
${ }^{4}$ In both the Oaxaca and Cotton-Neumark decomposition techniques, the difference in the natural log of average income between two groups is often decomposed, rather than the difference in the average income. The former approach allows the researcher to determine the percent of the income difference that can be attributed to a particular factor. We examine the rural-urban difference in average income rather than the rural-urban difference in the natural log of average income. This approach allows us to determine the dollar difference that can be attributed to differences in a particular factor, which should be useful information for policy makers. The dollar difference attributed to each characteristic is not reported in the results.
} 


\section{THE DATA AND THE RESULTS}

The AFI in a county is for 1989, while the remaining variables are for 1990 (except the employment growth and restructuring variables, which apply to the 1980-1990 period). The data for most variables are obtained from the U.S. Census Bureau's 1990 Census of the Population, which reports income for the year before the census, but reports the other characteristics included in Equation 2 for 1990. Other researchers that have conducted studies using Census Bureau data have also faced this problem. Since there is not expected to be any systematic difference between the pattern of AFI across counties in 1989 and the 1990, it is not expected that the results of this study will be affected by using 1989 income data instead of 1990 income data.

The means of each of the variables in Equation 2 for the pooled sample and for urban and rural counties are reported in Table 2. The AFI for the pooled sample of 1,264 counties is $\$ 33,459$. This varies from $\$ 29,525$ for the 933 rural counties to $\$ 44,549$ for the 331 urban counties, a difference of 50.9 percent. As will be demonstrated shortly, the rural-urban variation in county characteristics strongly contributes to the rural-urban variation in AFI.

TABLE 2

Means of Selected Variables by County Type

\begin{tabular}{lccc}
\hline Variable & Pooled Sample & Urban Counties & Rural Counties \\
\hline Average Family Income & $33,459.40$ & $44,549.12$ & $29,525.10$ \\
\% 65 and Older & 15.62 & 12.14 & 16.85 \\
\% Black & 9.03 & 13.05 & 7.61 \\
\% Other Minority & 3.98 & 6.53 & 3.08 \\
\% Female Headed & 12.55 & 16.60 & 11.12 \\
\% High School & 55.37 & 55.11 & 55.46 \\
\% College & 13.75 & 22.35 & 10.71 \\
Male LFPR & 69.72 & 74.53 & 68.02 \\
Female LFPR & 50.96 & 57.79 & 48.54 \\
Employment Growth & 0.228 & 0.345 & 0.186 \\
Restructuring & 0.112 & 0.096 & 0.117 \\
\% Goods Producing & 25.67 & 22.07 & 26.94 \\
\% State Union & 12.89 & 13.56 & 12.65 \\
\hline
\end{tabular}

Note: The difference between the mean of rural counties and of urban counties is statistically significant at the .01 level for all variables except \% State Union, which is statistically significant at the .05 level, and \% High School.

It also can be seen in Table 2 that there is substantial rural-urban variation for several of the independent variables in Equation 2. The percent of the population that is black is 71.5 percent higher in urban counties than in rural counties, and the percent of the population that is nonblack minority is 120 percent higher in urban counties than in rural counties. Likewise, the percent of families that are female headed (with no husband present) is 43.9 percent higher in urban counties than in rural counties. In terms of educational attainment, the percent of the 25year-old and older population that has a college degree is more than twice as high in urban counties than rural counties. Although the level of industrial restructur- 
ing 5 between 1980 and 1990 is only slightly higher in rural counties than urban counties, employment growth between 1980 and 1990 is 85.5 percent higher in urban counties than in rural counties.

Prior to discussing the urban-rural decomposition, we discuss the OLS results for the 1,264 counties in the pooled sample, as well as for the 933 rural counties and the 331 urban counties, separately. ${ }^{6}$ The results, which are reported in Table 3, indicate that AFI in a county is positively and significantly affected by the percent of the population that is black or nonblack minority. AFI is also positively and significantly affected by the percent of the 25 years of age and older population that graduated from college, the male labor force participation rate, and the amount of employment growth in the county between 1980 and 1990. In addition, AFI is higher in counties located in states with a relatively high level of unionization, and is higher in counties with a relatively high proportion of the workforce employed in goods-producing industries.

Among the demographic characteristics, the percent of families that are female headed has by far the largest effect on AFI. In the pooled sample, a 1 percentage point increase in the number of families that are female headed causes a $\$ 244$ decrease in AFI. An increase of 1 percentage point in the proportion of the population that is black or nonblack minority induces a $\$ 99$ and $\$ 109$ increase in a county's AFI, respectively. A change in the proportion of the population that is older than 64 causes no significant change in a county's AFI.

The effect of a county's human capital characteristics on its AFI is mixed. One of the educational characteristics, the percent of the 25-year-old and older population that graduated from college, has a statistically significant and positive effect on AFI. A 1 percentage point increase in this factor causes an increase in AFI of \$922. The percent of the population that graduated from high school (but not college), however, has a statistically significant, but much smaller, effect on a county's AFI. A 1 percentage point increase in this factor only causes an increase in AFI of $\$ 80$.

Among the economic variables, the male labor force participation rate positively affects AFI, with a 1 percentage point increase causing an increase in AFI of \$252. The female labor force participation rate is found to have a much smaller effect on AFI. A 1 percentage point increase in the female labor force participation rate only induces an increase of $\$ 81$ in AFI. Employment growth in a county is found to promote an increase in AFI, but the magnitude of the effect is fairly small. The results indicate that a 100 percent increase in a county's employment growth rate between 1980 and 1990 only induces a $\$ 1,167$ increase in the AFI of the county. Given that the average employment growth between 1980 and 1990 was 22.8

${ }^{5}$ The industrial restructuring variable is the Index of Structural Change (ISC), developed by Allen and Freeman (1997). It is the sum of the absolute value of changes in the share of employment in an industry (using an elevenindustry classification) between 1980 and 1990 divided by two. The value of the ISC for a county is approximately the percent of employment in 1990 that would need to shift to another industry to make the 1990 distribution of employment among industries the same as the 1980 distribution (Levernier, Partridge, and Rickman 1998).

${ }^{6}$ Using the Chow-test (see Greene 1997), we reject the hypothesis that the coefficients in the urban regression are equal to those in the rural regression. Therefore, running separate regressions for urban counties and rural counties is appropriate. 
percent, a county with average employment growth would only expect to experience a $\$ 266$ increase in AFI because of the employment growth, ceteris paribus. The effect of industrial restructuring between 1980 and 1990 has a statistically insignificant (at the .05 level) effect on AFI, however. The regression results further indicate that an increase of 1 percentage point in the unionization rate of the state where the county is located causes the county's AFI to increase by $\$ 384$, ceteris paribus. The final economic characteristic, the percent of the labor force employed in goods-producing industries, induces an increase of \$104 in AFI for each 1 percentage point increase. ${ }^{7}$

TABLE 3

OLS Regression Results of Average Family Income Model

\begin{tabular}{|c|c|c|c|}
\hline Variable & Pooled Sample & Urban Counties & Rural Counties \\
\hline Intercept & $\begin{array}{r}-11,507.0 \\
(4.79)\end{array}$ & $\begin{array}{r}-22,308.00 \\
(2.69)\end{array}$ & $\begin{array}{r}3,475.60 \\
(1.90)\end{array}$ \\
\hline$\% 65$ and Older & $\begin{array}{c}69.25 \\
(1.49)\end{array}$ & $\begin{array}{r}675.39 a \\
(6.32)\end{array}$ & $\begin{array}{r}-135.81^{\mathrm{a}} \\
(3.06)\end{array}$ \\
\hline$\%$ Black & $\begin{array}{l}98.78^{a} \\
(6.00)\end{array}$ & $\begin{array}{r}228.58^{\mathrm{a}} \\
(5.82)\end{array}$ & $\begin{array}{r}93.47^{a} \\
(5.64)\end{array}$ \\
\hline$\%$ Other Minority & $\begin{array}{r}108.58^{\mathrm{a}} \\
(4.95)\end{array}$ & $\begin{array}{r}182.52^{\mathrm{a}} \\
(3.58)\end{array}$ & $\begin{array}{l}43.39 \mathrm{~b} \\
(2.22)\end{array}$ \\
\hline$\%$ Female Headed & $\begin{array}{r}-243.85^{a} \\
(5.28)\end{array}$ & $\begin{array}{r}-670.83^{a} \\
(6.74)\end{array}$ & $\begin{array}{r}-376.20^{a} \\
(7.20)\end{array}$ \\
\hline \% High School & $\begin{array}{l}79.82^{a} \\
(3.27)\end{array}$ & $\begin{array}{c}-52.30 \\
(0.73)\end{array}$ & $\begin{array}{r}168.94^{\mathrm{a}} \\
(8.09)\end{array}$ \\
\hline$\%$ College & $\begin{array}{l}922.08^{a} \\
(25.19)\end{array}$ & $\begin{array}{l}770.92^{a} \\
(11.03)\end{array}$ & $\begin{array}{r}532.50^{\mathrm{a}} \\
(9.02)\end{array}$ \\
\hline Male LFPR & $\begin{array}{r}251.50^{\mathrm{a}} \\
(7.02)\end{array}$ & $\begin{array}{r}403.02^{\mathrm{a}} \\
(3.92)\end{array}$ & $\begin{array}{r}138.21^{\mathrm{a}} \\
(5.25)\end{array}$ \\
\hline Female LFPR & $\begin{array}{l}81.28 \mathrm{~b} \\
(2.10)\end{array}$ & $\begin{array}{r}139.73 \\
(1.59)\end{array}$ & $\begin{array}{l}88.94^{\mathrm{a}} \\
(2.55)\end{array}$ \\
\hline Employment Growth & $\begin{array}{r}1,167.20^{\mathrm{a}} \\
(3.45)\end{array}$ & $\begin{array}{r}2,846.20^{\mathrm{a}} \\
(4.20)\end{array}$ & $\begin{array}{r}489.63 \\
(1.63)\end{array}$ \\
\hline Restructuring & $\begin{array}{r}5,871.30 \\
(1.89)\end{array}$ & $\begin{array}{r}13,646.00 \\
(1.54)\end{array}$ & $\begin{array}{c}6,148.40^{\mathrm{b}} \\
(2.24)\end{array}$ \\
\hline$\%$ Goods Producing & $\begin{array}{r}104.22^{\mathrm{a}} \\
(6.70)\end{array}$ & $\begin{array}{r}155.67^{\mathrm{a}} \\
(2.97)\end{array}$ & $\begin{array}{l}60.70^{a} \\
(4.10)\end{array}$ \\
\hline$\%$ State Union & $\begin{array}{l}384.19^{a} \\
(11.38)\end{array}$ & $\begin{array}{r}607.91^{\mathrm{a}} \\
(8.19)\end{array}$ & $\begin{array}{r}180.14^{a} \\
(6.56)\end{array}$ \\
\hline West & $\begin{array}{r}-4,358.80^{\mathrm{a}} \\
(7.27)\end{array}$ & $\begin{array}{r}-1,752.80 \\
(1.84)\end{array}$ & $\begin{array}{r}-4,492.90^{a} \\
(7.53)\end{array}$ \\
\hline Midwest & $\begin{array}{r}-3,332.50^{\mathrm{a}} \\
(7.40)\end{array}$ & $\begin{array}{r}-3,210.50^{a} \\
(3.17)\end{array}$ & $\begin{array}{r}-3,103.80^{a} \\
(7.96)\end{array}$ \\
\hline Northeast & $\begin{array}{r}769.95 \\
(0.89)\end{array}$ & $\begin{array}{r}1,272.10 \\
(0.94)\end{array}$ & $\begin{array}{r}-1,716.90^{a} \\
(2.88)\end{array}$ \\
\hline $\mathrm{N}$ & 1,264 & 331 & 933 \\
\hline $\begin{array}{l}\mathbf{R}^{2} \\
\text { F-Value }\end{array}$ & $\begin{array}{c}.800 \\
333.63^{a}\end{array}$ & $\begin{array}{c}.845 \\
114.55^{a}\end{array}$ & $\begin{array}{c}.612 \\
96.30^{a}\end{array}$ \\
\hline
\end{tabular}

Note: The coefficients of \% 65 and Older, \% Black, \% Other Minority, Restructuring, West, Midwest, and Northeast are tested using a two-tailed test, since there is no a priori expectation regarding their signs. All other variables are tested using a one-tailed test. The absolute value of the t-statistic is shown in parentheses.

a denotes significance at the .01 level.

$\mathrm{b}_{\text {denotes significance at the } .05 \text { level. }}$

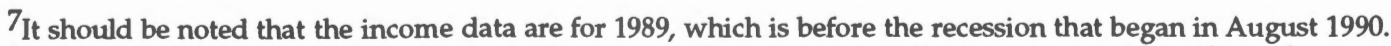
Since goods-producing industries are cyclically sensitive industries, the percentage of total employment employed in goods-producing industries would likely be less during a recession than during an economic expansion period. As such, the results of this study regarding the effect of goods-producing employment may be less applicable to a recession than an expansion. 
The regional geographic variables also significantly affect AFI. Table 3 indicates that counties located in the West and Midwest Census regions have an AFI about $\$ 4,359$ and $\$ 3,333$ lower, respectively, than that of a county located in the South Census region (the omitted category), after controlling for other factors. Location in the Northeast Census region does not significantly affect a county's AFI. ${ }^{8}$

The regression results reveal some large rural-urban differences in the effect that certain variables have on the AFI in a county. The effect of demographic variables, for example, varies substantially between rural and urban counties. A 1 percentage point increase in the percent of the population that is 65 years of age or older increases AFI in urban counties by $\$ 675$, but decreases AFI in rural counties by $\$ 136$. The percent of the population that is black induces an increase of $\$ 229$ in the AFI of a typical urban county, but only induces an increase of $\$ 93$ in a typical rural county. Similarly, a 1 percentage point increase in the percent of families headed by a female (with no husband present) decreases AFI in an urban county by $\$ 671$, but only causes a $\$ 376$ decrease in AFI in a rural county.

The above finding suggests that the income of people 65 years old and older is relatively high in urban areas but relatively low in rural areas. One possible explanation for this is related to the fact that urban areas with a relatively high proportion of people that are 65 years old and older have a relatively high proportion of retirees. If these retirees have chosen to reside in the urban area because of its availability of health, cultural, and transportation facilities, rather than residing in an alternative area, they may be relatively wealthy people who have the financial resources that enable them to migrate to where they want to retire. Older urbanites may be more affluent than their rural counterparts and more likely to have investments that generate income. A disproportionate number of people retiring in rural areas, with their lack of certain amenities, may be choosing a rural area because they do not have the financial resources to migrate elsewhere, rather than because they find a rural area a desirable place to retire to. If these people are less affluent than their urban counterparts, then they are probably less likely to have much in the way of income-generating investments.

The finding regarding the rural-urban difference in the effect of the black population on AFI indicates that a county's AFI increases as its population becomes more racially homogeneous, ceteris paribus. A possible explanation for this finding relates to racial discrimination in earnings. Discrimination lowers the earnings of persons in the group that is discriminated against. If the extent of racial discrimination in an area decreases as the population of the area becomes more racially homogeneous, though, the "cost of being black" in such an area is likely to be much less than in an area where the population is less racially homogeneous. As such, earnings of blacks would likely be relatively higher in areas

\footnotetext{
${ }^{8} \mathrm{We}$ also ran a set of regressions in which a South/non-South dummy, rather than three regional dummies, was included in the model. This regression measures the income difference between a county in the South and a county in the non-South, ceteris paribus. The non-South group, of course, would contain counties from the West, Midwest, and Northeast. The variable is statistically significant (at the .05 level) for both the rural and urban regressions. The value of the coefficient on the South dummy indicates that a county located in the South Census region has an AFI approximately $\$ 3,326$ higher than a similar county located outside the South Census region. The complete results of this set of alternative regressions are not reported in this paper.
} 
where the proportionate black population is relatively high. Since urban counties, on average, have a higher percent of the population that is black than rural counties, urban counties tend to be more racially homogeneous in terms of the black population.

The effect of the human capital characteristics of a county, like the demographic characteristics, also displays substantial rural-urban variation. A 1 percentage point increase in the percent of the 25-year-old or older population that graduated from college increases AFI in an urban county by $\$ 771$, while it causes only a $\$ 533$ increase in AFI in a rural county. A 1 percentage point increase in the percent of the population that graduated from high school (but not college) increases AFI in rural counties by $\$ 169$, but does not significantly affect income in urban counties.

In addition to the above-mentioned rural-urban differences, evidence of rural-urban differences in the coefficients of the employment-related variables is revealed in Table 3. A 1 percentage point increase in the male labor force participation rate causes a $\$ 403$ increase in AFI in urban counties, but the corresponding increase in rural counties is only $\$ 138$. The magnitude of the coefficient of the female labor force participation rate is also larger in urban counties than in rural counties (although the urban coefficient is significant only at the .10 level). The results further indicate that industrial restructuring influences AFI in only rural counties. The percent of the labor force employed in goods-producing industries significantly affects income in both rural and urban counties, but the effect in urban counties is more than twice as large as in rural counties. The effect of state unionization is much higher for urban counties than for rural counties. A 1 percentage point increase in the proportion of the state's labor force that is unionized increases AFI in urban counties by about $\$ 608$, but by only $\$ 180$ in rural counties. One possible reason for this finding may be that unionized jobs, which typically pay higher wages than similar nonunion jobs, are primarily in urban areas. As the workforce in a state becomes more unionized, the higher wages associated with labor unions are likely to disproportionately affect urban workers.

The effect of geographic location on a county's AFI is mixed. In rural counties, the resuits indicate that AFI is significantly affected by its location in the United States. For urban counties, though, the effect of geographic location is statistically much weaker, since only one of the three regional dummies is significant (at the .05 level). ${ }^{9}$ A rural county located in the West, Midwest, or Northeast Census regions is expected to have lower AFI than an otherwise similar county located in the South Census region. This result is somewhat surprising, as AFI for rural counties in the South Census region is lower than AFI for rural counties in the other three Census regions. ${ }^{10}$ The results then imply that much of the rural South's income deficit is

${ }^{9} \mathrm{~A}$ Chow-test on the joint significance of the three regional dummies in the urban regression indicates that the three regional dummies jointly have a statistically significant effect (at the .01 level) on the AFI of urban counties. ${ }^{10}$ To analyze regional income differences further, each of the 1,264 counties in the pooled sample was assigned to its appropriate Census region and rural/urban class. The mean AFI for rural counties in the South Census region is $\$ 28,722$. Also, the AFI for rural counties in the West Census region is $\$ 31,485$, while that for the rural counties in the Midwest Census region is $\$ 29,366$ and that for rural counties in the Northeast Census region is $\$ 33,966$. The corresponding AFI for urban counties is $\$ 41,458$ in the South Census region, $\$ 45,134$ in the West Census region, $\$ 43,632$ in the Midwest Census region, and \$55,152 in the Northeast Census region. 
caused by the relative characteristics of rural counties in the South. Holding these characteristics constant across regions, rural counties in the South would be expected to have an income that is between $\$ 1,717$ and $\$ 4,493$ higher than a similar rural county located outside the South. ${ }^{11}$

The results reported so far document differences between returns to various characteristics based on whether a county is rural or urban. In Table 4, the decomposition of the difference in AFI between rural and urban counties is reported using both the Oaxaca decomposition technique and the Cotton-Neumark extension of the technique. The difference in the mean AFI between rural and urban counties is $\$ 15,025$ and is denoted as the "Total Differential" in Table 4. The total differential is composed of two parts: an "Attribute-Based" (explained) part and a "Non-Attribute-Based" (unexplained) part. The attribute-based differential is the part of the rural-urban income differential that is caused by differences in average characteristics between rural and urban counties. The part of the income differential that is not accounted for by differences in rural-urban characteristics is the unexplained part.

\section{TABLE 4}

Decompositions of Rural-Urban Average Family Income Differentials (Differentials are in 1989 dollars)

\begin{tabular}{lcc}
\hline & Oaxaca Decomposition & Cotton-Neumark Decomposition \\
\hline Total Differential & $\$ 15,025$ & $\$ 15,025$ \\
Attribute-Based (Explained) Part & $\$ 8,488$ & $\$ 7,403$ \\
Non-Attribute-Based (Unexplained) Part & $\$ 6,537$ & $\$ 7,622$ \\
\hline
\end{tabular}

The results in Table 4 indicate that, based on differences in the average attributes between rural and urban counties alone, a typical rural county would have an AFI between $\$ 7,403$ and $\$ 8,488$ less than that of a typical urban county. The relative weakness of the characteristics of rural counties then explains only between 49 percent and 56 percent of the $\$ 15,025$ rural-urban difference in AFI. The unexplained part of the decomposition is between $\$ 6,537$ and $\$ 7,622$. Thus, even if rural counties had the same average characteristics as urban counties, the results of this study indicate that a typical rural county would still have an AFI that is about $\$ 7,000$ less than a typical urban county. ${ }^{12}$ In other words, if the characteristics of rural counties were equal to those of urban counties, approximately 47 percent of the total income difference between rural and urban counties would still remain. In the gender and race studies, this unexplained portion would generally be attributed to discrimination. In this study, the difference can be

\footnotetext{
${ }^{11}$ In the alternative regressions mentioned in Footnote 8, where the three regional dummies were replaced with a single South/non-South dummy, a rural county in the South Census region is found to have an AFI that is $\$ 3,308$ more than a rural county in the non-South, ceteris paribus. Further, an urban county in the South Census region is found to have an AFI that is $\$ 2,177$ higher than an urban county in the non-South region, ceteris paribus.

12We also ran a set of regressions in which a rural dummy was included in the pooled model (Model 1 in Table 3). The coefficient on the variable is statistically significant (at the .01 level) and has a magnitude of $-6,290$, indicating that a typical rural county has an AFI that is $\$ 6,290$ less than a typical urban county, ceteris paribus. This amount is slightly less than the $\$ 6,537$ to $\$ 7,622$ range indicated in the Oaxaca and Cotton-Neumark decompositions. The complete results for this set of regressions are not reported in the paper.
} 
considered an income disadvantage of rural counties in addition to what is explained by their characteristics relative to those of urban counties.

\section{SUMMARY AND POLICY IMPLICATIONS}

This study has examined the rural-urban difference in average family income. While the regression results for the pooled sample of 1,264 counties are generally what is expected, there is evidence of a rural-urban variation in the magnitude, significance, and even the sign of several coefficients. Demographic characteristics, such as the percent of a county's population that is black and the percent of the families that are female headed, both have a much stronger effect on average family income in urban counties than in rural counties. Likewise, the two human capital characteristics, the percent of the population that graduated from college and the percent of the population that graduated from high school (but not college), both exhibit substantial rural-urban variation.

The effect of the employment-related variables also exhibit rural-urban variation. For the female labor force participation rate and industrial restructuring, the effect on average family income is statistically significant and positive only in rural counties. Employment growth, though, has a statistically significant effect on average family income only in urban counties. The effect of the male labor force participation rate and the percent of employment that is in goodsproducing industries is much stronger in urban counties that rural counties. From a policy perspective, this implies that public policies to promote employment growth or that increase the male labor force participation will likely be more effective at increasing average family income in urban counties than in rural counties.

By examining the rural-urban differences, like those reported in Table 3, policy makers who are striving to increase average family income in a county can focus their efforts on changing those factors that will achieve the desired objective. By ignoring the fact that factors that significantly affect average family income in urban counties may not affect it in rural counties, policy makers may inadvertently focus their efforts on changing the wrong factors. Such policies are likely to be ineffective at achieving the desired objective.

While it has often been argued that the income of rural regions lags behind that of urban areas because of the relatively weak characteristics of rural areas, this study finds evidence that the urban-rural income differential is only partially explained by the relatively weak characteristics of rural counties. Compared to urban counties, for example, rural counties have a low male labor force participation rate, low employment growth, and a low proportion of the population that graduated from college. However, the rural-urban differences in characteristics only account for between roughly $\$ 7,400$ and $\$ 8,500$ of the $\$ 15,000$ rural-urban income differential, depending on which decomposition technique is used.13 These figures should be interpreted, however, with the understanding that they will be affected if relevant variables are omitted from the regressions. In other ${ }^{13}$ In the Oaxaca decomposition technique, the magnitude of the explained portion and unexplained portion is sensitive to whether rural counties or urban counties are chosen as the base. The rural counties have been chosen as the base in this study. The Cotton-Neumark technique corrects this shortcoming. 
words, if the regressions suffer from omitted-variable bias, some of the unexplained portion of the income difference is likely to be actually caused by the omitted variables and not by a rural disadvantage.

From a policy perspective, the decomposition results suggest that policies that make the economic, demographic, and human capital characteristics of rural counties more similar to those of urban counties will likely bring about some convergence of the average family income of rural and urban counties. It also suggests, however, that such policies will not be entirely successful in equating the average family income of rural and urban counties. There is apparently an unobserved inherent characteristic in rural counties, perhaps related to their historical or cultural development, that causes rural counties to lag behind urban counties, even when controlling for rural-urban differences in relevant characteristics.

\section{REFERENCES}

Allen, S.G., and R.B. Freeman. "Quantitative Flexibility in the U.S. Labor Market." In E. Amadeo and S. Horton (eds.) Labour Productivity and Flexibility. London: Macmillan, 1997.

Becker, G.S. Human Capital: A Theoretical and Empirical Analysis, With Special Reference to Education. Chicago: University of Chicago Press, 1975.

Bell, D.N.F. "Regional Output, Employment and Unemployment Fluctuations." Oxford Economic Papers 33 (1981), 42-60.

Bellante, D., and C. Kogut. "Intra-Regional Wage Variation and Regional Disparity in the Relative Earnings of Blacks." Journal of Economics and Finance 20 (1996), 15-31.

Bound, J., and Harry J. Holzer. "Demand Shifts, Population Adjustments, and Labor Market Outcomes During the 1980s." Journal of Labor Economics 18 (2000), 20-54.

Brechling, F. "Trends and Cycles in British Regional Unemployment." Oxford Economic Papers 19 (1967), 1-21.

Byers, J.D. "The Cyclical Sensitivity of Regional Unemployment: An Assessment." Regional Studies 25 (1990), 447-453.

. "Testing for Common Trends in Regional Unemployment." Applied Economics 23 (1991), 1087-1092.

Carlstrom, C.T., and C.D. Rollow. "Regional Variations in White-Black Earnings." Federal Reserve Bank of Cleveland Economic Review 34 (1998), 10-22.

Chapman, P.G. "The Dynamics of Regional Unemployment in the U.K., 19741989." Applied Economics 23 (1991), 1059-1064.

Cotton, J. "On the Decomposition of Wage Differentials." Review of Economics and Statistics 70 (1988), 236-243.

Danziger, S. "The Economy, Public Policy, and the Poor." In H. R. Rodgers, Jr. (ed.) Beyond Welfare: New Approaches to the Problem of Poverty in America. Armonk, NY: M. E. Sharpe, 1988.

Gaynor, P.E., and G.C. Durden. "The Cost of Being Nonwhite and the Added Cost of Being Female in the South and Southwest." The Review of Regional Studies 27 (1997), 195-209. 
Gordon, I.T. "The Cyclical Sensitivity of Regional Unemployment and Unemployment Differentials." Regional Studies 19 (1985), 95-110.

Greene, W.H. LIMDEP Version 7.0 User's Manual. Bellport, NY: Econometric Software, Inc., 1995.

. Econometric Analysis. Upper Saddle River, NJ: Prentice-Hall, Inc., 1997.

Hirsch, B.T., and D.A. McPherson. "Union Membership and Coverage Files from the Current Population Surveys: Note." Industrial and Labor Relations Review 46 (1993), 574-578.

Hotchkiss, J.L. "A Time Series Analysis of Disaggregate U.S. Unemployment." Journal of Macroeconomics 13 (1991), 701-711.

Hyclak, T., and G. Lynch. "An Empirical Analysis of State Unemployment Rates in the 1970s." Journal of Regional Science 20 (1980), 377-386.

Levernier, W., M.D. Partridge, and D.S. Rickman. "Differences in Metropolitan and Non-Metropolitan U.S. Income Inequality: A Cross-County Comparison." Journal of Urban Economics 44 (1998), 272-290.

Loewenstein, M.A., and J.R. Spletzer. "General and Specific Training: Evidence and Implications." Journal of Human Resources 34 (1999), 710-733.

Mincer, J. "On-the-Job-Training: Costs, Returns and Some Implications." Journal of Political Economy 70 (1962), S50-S79.

Mincer, J., and S. Polachek. "Family Investments in Human Capital: Earnings of Women" Journal of Political Economy 82 (1974), S76-S108.

Negrey, C., M.B. Zickel, and J.M. Fenn. "Industrial Restructuring and Regional Household Income Growth." Regional Studies 32 (1998), 103-111.

Neumark, D. "Employers' Discriminatory Behavior and the Estimation of Wage Discrimination." Journal of Human Resources 23 (1988), 279-295.

Oaxaca, R. "Male-Female Wage Differentials in Urban Labor Markets." International Labor Market Review 14 (1973), 693-709.

Renkow, M. "Income Non-Convergence and Rural-Urban Earnings Differentials: Evidence from North Carolina." Southern Economic Journal 62 (1996), 1017-1028. Sawhill, I. "Poverty in the U.S.: Why is it so Persistent?" Journal of Economic Literature 26 (1988), 1073-1119.

Schiller, B. The Economics of Poverty and Discrimination. Englewood Cliffs, NJ: Prentice-Hall, 1998.

Schultz, T.W. "Investment in Human Capital" American Economic Review 51 (1960), 1-17.

Simon, J.L. "Why Don't State Incomes Converge? Effective Worker Pay Does Not Differ Among States." Economics of Education Review 12 (1993), 105-115.

Tiller, R.B., and R.W. Bednarzik. "The Behavior of Regional Unemployment Rates over Time-Effects on Dispersion and National Unemployment." Journal of Regional Science 23 (1983), 479-499.

U.S. Census Bureau. 1990 Census of the Population. STF3A CD-ROM. "Historical Poverty Tables, Table 8, Poverty of People by Residence: 1959-1998." Current Population Survey. March 1998. <http://www.census.gov/hhes/poverty/histpov/hstpov8.html> 